\title{
Scorpion-shaped pancreas together with an arterial variation complex*
}

\author{
Mehmet Ali İkidağ ${ }^{1}$, Mehmet Ali Cücé2, Şinasi Özkılıç, \\ Erdal Uysal ${ }^{4}$, Salih Murat Akkın \\ ${ }^{1}$ Department of Radiology, School of Medicine, SANKO University, Gaziantep, Turkey \\ ${ }^{2}$ Department of Radiology, Sani Konukoğhu Hospital, Gaziantep, Turkey \\ ${ }^{3}$ Department of Nuclear Medicine, School of Medicine, SANKO University, Gaziantep, Turkey \\ ${ }^{4}$ Divison of Transplant Surgery, Department of General Surgery, School of Medicine, SANKO University, Gaziantep, Turkey \\ 'Department of Anatomy, School of Medicine, SANKO University, Gaziantep, Turkey
}

\begin{abstract}
There is a range of well-described anatomic variations and developmental anomalies of the pancreas in the literature Although some of these variations are extremely uncommon, knowledge of these abnormalities is essential for avoiding misdiagnosis and managing pancreatic pathologies clinically. In this paper, we present an anatomical variation observed during thoracoabdominal CT examination of a 33-year-old female. This patient presented with left chest pain and had undergone splenectomy six years ago and left thoracotomy one year ago, both for hydatid cyst. The case showed that the tail of pancreas raised upward and then anteriorly, resembling the tail of a scorpion, and was accompanied by a right hepatic artery that originated from the superior mesenteric artery and a left accessory renal artery. Because no similar case has been reported in the available literature, our opinion is that physicians should also be familiar with scorpion-shaped pancreas that can be termed as 'pancreas scorpiforme' anatomically.
\end{abstract}

Keywords: anomaly; pancreas; tail of pancreas; variation

Anatomy 2016;10(1):75-77 @2016 Turkish Society of Anatomy and Clinical Anatomy (TSACA)

\section{Introduction}

There is a range of well-described anatomic variations and developmental anomalies of the pancreas in the literature. These include pancreas divisum, annular pancreas, ectopic pancreas, total or partial agenesis, and variations of the course and configuration of pancreatic ducts. ${ }^{[1-3]}$ Although some of these variations are extremely uncommon, knowledge of these abnormalities is essential for avoiding misdiagnosis and managing pancreatic pathologies clinically. ${ }^{[3,4]}$ Here we present an anatomical variation observed during a thoracoabdominal CT examination in which the pancreatic tail raised upward and then anteriorly, resembling the tail of a scorpion, and it was accompanied by a right hepatic artery originating from the superior mesenteric artery, and a left accessory renal artery.

\section{Case Report}

The case was a 33-year-old female admitted to thoracic surgery department with the complaint of left chest pain, who had splenectomy six years ago and left thoracotomy one year ago, both for hydatid cyst. Chest $\mathrm{X}$-ray revealed infiltration in the left lower lobe, and the patient was referred to thoracic and abdominal CT in order to exclude lung cyst recurrence and possible accompanying liver cyst. CT revealed left lower lobe infiltration, band atelectasis, and mild pleural thickening. The left lobe of the liver was reaching out to left sub-diaphragmatic

*This case was presented at the XXIV International Symposium on Morphological Sciences (ISMS), 2-6 September 2015, Istanbul, Turkey. 


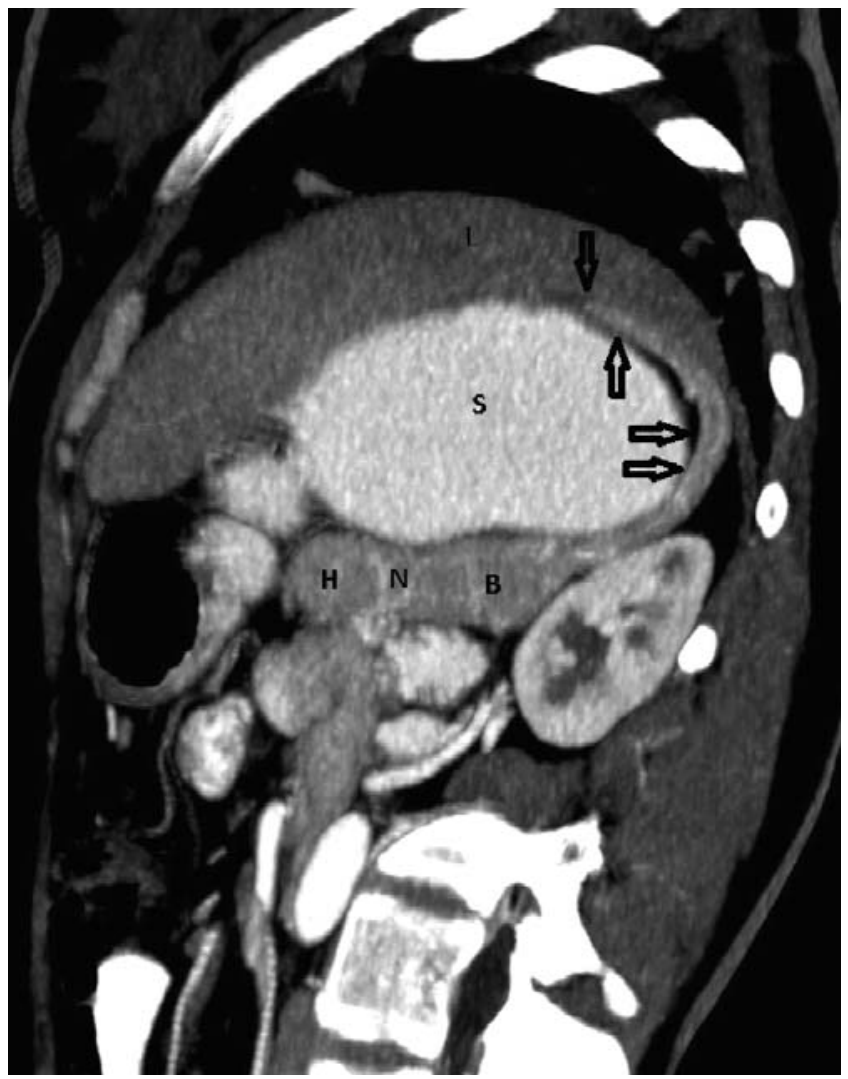

Figure 1. Oblique sagittal MIP (maximum intensity projection) CT image in arterial phase depicts elongated, high rising and forward orienting tail of pancreas (arrows), resembling the tail of a scorpion. B: body of pancreas; $\mathrm{H}$ : head of pancreas; $\mathrm{N}$ : neck of pancreas; L: liver; S: stomach.

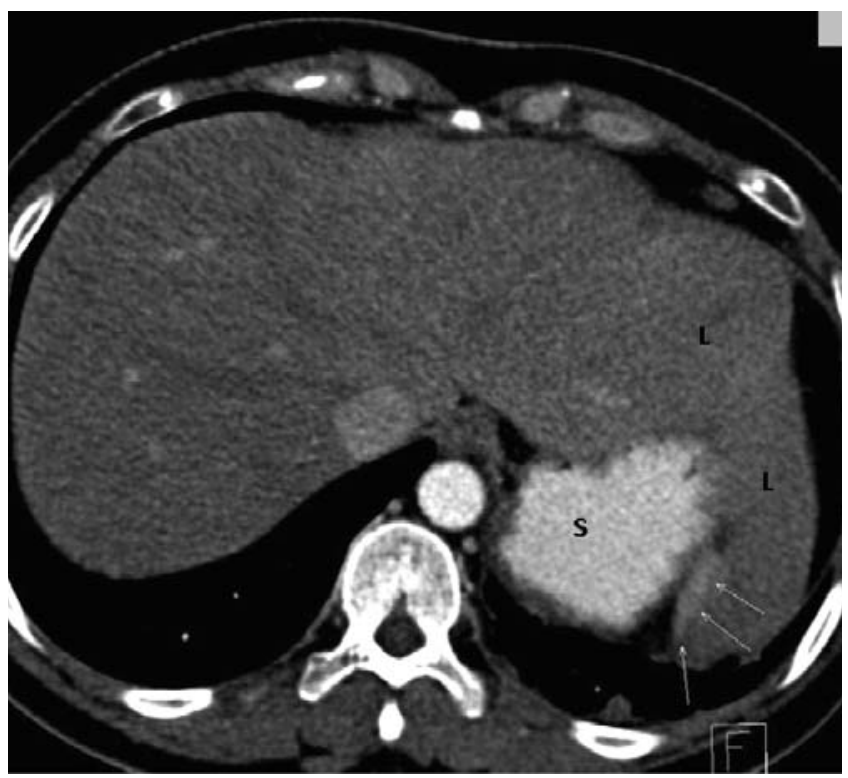

Figure 2. Arterial phase axial CT image shows relation of the tail of pancreas (arrows) to the left lobe of liver (L), and stomach (S). region. An elongated tail of pancreas was noticed, which was ascending superiorly and then orienting anteriorly (Figure 1), with a close relation to the medial aspect of the left lobe of liver and lateral aspect of fundus of stomach (Figure 2). Right hepatic artery was originating from the superior mesenteric artery. Celiac trunk, splenic artery, choledoch, bile ducts and pancreatic canal were evaluated as normal. There was a left accessory renal artery. Left lower pneumonia was considered as the reason of chest pain, and patient relieved after antibiotic treatment.

\section{Discussion}

In the fourth week of gestation, the primitive foregut gives rise to dorsal and ventral buds, which form the two pancreatic ducts separately (Wirsung and Santorini). The ventral bud forms the posterior head and uncinate process of the pancreas, whereas the dorsal bud forms the anterior head, body, and tail. The ventral pancreas rotates clockwise posterior to the duodenum and comes into contact with the dorsal pancreas to develop into the future pancreatic neck. This fusion process occurs at the seventh gestational week, and the majority of pancreatic and ductal variations are attributed to this complex course of pancreatic development..$^{[1-5]}$ An overgrowth of dorsal bud in the gestational life may be responsible for the tail variation in our case.

Pancreatic and ductal variations include pancreas divisum, annular pancreas, dorsal agenesis or hypoplasia, accessory pancreatic lobe, and ectopic pancreas. ${ }^{[2]}$ Agenesis of ventral pancreas and complete agenesis of the pancreas are not compatible with life. ${ }^{[6]}$ Annular pancreas is a rare entity in which the head of the pancreas encircles the medial side of the second part of duodenum and may cause obstruction symptoms such as vomiting in the neonatal period, while other variations are mostly encountered incidentally in the adulthood. ${ }^{[2,4]}$ Pancreas divisum, the most common anomaly, where ducts of Wirsung and Santorini drain into the duodenum separately, is one of the causes of recurrent pancreatitis, ${ }^{[7,8]}$ and is encountered in $3-22 \%$ of the population. ${ }^{[9]}$ Dorsal agenesis of the pancreas is rare, and associated pancreatitis has been reported. ${ }^{[10]}$

Other variations like ansa pancreatica, accessory pancreatic lobe, bifid tail of pancreas, ectopic pancreas and ectopic spleen in the tail of pancreas are quite rare..$^{[2,4]}$

Because no similar case has been reported in the available literature, our opinion is that physicians should also be familiar with such scorpion-shaped pancreas cases that can be termed as 'pancreas scorpiforme' anatomically. 


\section{References}

1. Kozu T, Suda K, Toki F. Pancreatic development and anatomical variation. Gastrointest Endosc Clin N Am 1995;5:1-30.

2. Bergman RA, Afifi AK, Miyauchi R. Pancreas. [Internet] Illustrated encyclopedia of human anatomic variation: Opus IV: Organ systems: digestive system and spleen. [Retrieved: 2015 May 15] Available at: http://www.anatomyatlases.org/AnatomicVariants/OrganSystem/T ext/Pancreas.shtml

3. Lal A, Pavunesan SK, Mahalingam H, Garg M, Sinha SK, Khandelwal N. A triad of complete dorsal pancreatic agenesis, pancake kidney and bicornuate uterus. An association or an incidental finding: first case in literature. JOP 2015;16:189-91.

4. Türkvatan A, Erden A, Türkoğlu MA, Yener Ö. Congenital variants and anomalies of the pancreas and pancreatic duct: imaging by magnetic resonance cholangiopancreaticography and multidetector computed tomography. Korean J Radiol 2013:14:905-13.
5. Schulte SJ. Embryology, normal variation, and congenital anomalies of the pancreas. In: Stevenson GW, Freeny PC, Margulis AR, Burhenne HJ, editors. Margulis' and Burhenne's alimentary tract radiology. 5th ed. St. Louis (MO): Mosby; 1994. p. 1039-51.

6. Voldsgaard P, Kryger-Baggesen N, Lisse I. Agenesis of pancreas. Acta Paediatr 1994;83:791-3.

7. Levy MJ, Geenen JE. Idiopathic acute recurrent pancreatitis. Am J Gastroentereol 2001;96:2540-55.

8. Morgan DE, Logan K, Baron TH, Koehler RE, Smith JK. Pancreas divisum: implications for diagnostic and therapeutic pancreatography. Am J Roentgenol 1999;173:193-8.

9. White JJ, Roberts ZN, Gest TR, Belae EG. Pancreas divisum: a common developmental variant that deserves attention in preclinical medical education. Clin Anat 2014;27:1038-45.

10. Uygur Bayramiçli O, Dabak R, Kiliçoglu G, Dolapçioglu C, Oztas D. Dorsal pancreatic agenesis. JOP 2007;8:450-2.

Correspondence to: Mehmet Ali lkidağ, MD

Department of Radiology, School of Medicine,

SANKO University, Gazimuhtar Paşa Bulvarı No: 36,

27090, Gaziantep, Turkey

e-mail: maikidag@sanko.edu.tr

Conflict of interest statement: No conflicts declared.

\footnotetext{
This is an open access article distributed under the terms of the Creative Commons Attribution-NonCommercial-NoDerivs 3.0 Unported (CC BY-NCND3.0) Licence (http://creativecommons.org/licenses/by-nc-nd/3.0/) which permits unrestricted noncommercial use, distribution, and reproduction in any medium, provided the original work is properly cited. Please cite this article as: İkidağ MA, Cüce MA, Özkılıç Ş, Uysal E, Akkın SM. Scorpion-shaped pancreas together with an arterial variation complex. Anatomy 2016;10(1):75-77.
} 